\title{
Research on the Evaluation Index System of the Taxi Operation and Service in Airport Hubs
}

\author{
Min Zhong1, Yi Liu',a \\ ${ }^{1}$ Big data and Information Management Department, Civil Aviation Management Institute of China, Beijing, China
}

\begin{abstract}
Passengers changing to taxis in airport hubs are facing problems such as complicated transfer lines, long transfer distance and time, stranded at taxi stands, and imperfect emergency safeguard measures. Combining with the trend of smart passenger services under the development of new generation of information technology, this paper constructs a set of taxi operation and service evaluation index system reflecting unique attributes of the airport hub collection and distribution system. The index system considers the rationality of taxi infrastructure configuration, the matching of passenger service facilities, collection and distribution efficiency, transfer efficiency, etc. It also discusses index quantification and evaluation methods. Aiming at the real-time prediction of inbound flight passenger flow, taxi sharing rate and taxi capacity, the realization process of prediction models is proposed based on the big data method. Meanwhile, combining with the combing of comprehensive transportation operation information systems of hubs, it proposes to extract data from information systems to calculate some index values. The establishment of this index system can provide a strong reference for the evaluation of other transportation modes and the overall hub, and provide decision support for the optimization and improvement of taxi dispatch and overall operation and service of airport hubs.
\end{abstract}

\section{Introduction}

With the continuous development of the civil aviation industry, airport passenger flow has increased year by year, which has brought great challenges to the operational support capabilities and passenger distribution capabilities of airport hubs. On the one hand, the unsmooth, inconvenient and discontinuous transfer of passengers in the hub will reduce passenger satisfaction; on the other hand, the large-scale passenger detention implies potential safety hazards ${ }^{[1]}$. Therefore, improving the transfer connection efficiency and passenger service experience is an important goal to improve the hub collection and distribution system whose key feature that reflects the efficiency is the rapid evacuation of passenger flow. The Airport hub collection and distribution system connects the hub with various transportation modes and the passenger flow sharing of taxis plays an important role in large airport hubs at home and abroad. However, there are some problems in the evacuation of taxi passengers, such as: complicated passenger transfer lines, long transfer distance, long average waiting time for passengers at taxi station and taxi drivers at waiting area during peak hours, passengers stranded at taxi stands, imperfect emergency safeguard measures, etc. These problems have restricted the improvement of the overall operation efficiency and passenger service quality of the hub. Whether the passenger flow for changing to taxis

\footnotetext{
a Corresponding author: liuyi@camic.cn
}

can be evacuated quickly has become an urgent problem to be solved in various airport hubs.

Scholars have carried out some evaluation studies on the operation and services of comprehensive passenger hubs ${ }^{[2-6]}$, but because the airport hub has its unique attributes different from general hubs, the significance of reference of past research results is not very strong, and the evaluation research specifically for airport hubs is still in its infancy. In particular, there is still a lack of in-depth research on a specific mode of transportation in airport hubs. In this article, the aim of this study is to focus on the sharing of taxi capacity at the airport hub, combining with the evacuation process of passengers arriving at the airport, to study the evaluation index system construction of the diversion and evacuation of passengers who transfer to taxis. The evaluation index system takes airport hubs' unique attributes and smart passenger services into account which are a major contribution of this article.

\section{Construction of taxi operation and service evaluation index system}

\subsection{Research on the construction of evaluation index system}

This study evaluates the guarantee capacity, operation efficiency and service level of the taxi capacity by 
constructing a systematic index system. The airport hub collection and distribution system is comprehensive and complex which provides passengers with functions such as transportation production organization, ground transportation, information services, emergency services, and self-service. Compared with other comprehensive passenger hubs, airport hubs have their own unique attributes in addition to the common characteristics of general hubs. First, the airport hub has airside and landside, and the external environment is more complicated. The connection between the interchange stations, terminals and passenger rapid transit system is the key to the success of the comprehensive transportation hub. Second, the airport hub is dominated by aviation. Its main function is to complete the conversion for passengers between air and ground transportation, and to ensure the rapid and efficient distribution of passengers at the airport. Third, ensuring the consistency of service quality of air passenger travel chain is the key to improving the service quality of the hub ${ }^{[7]}$.

Based on the above functions of the airport hub, the evaluation objectives of taxi operation and service are divided into nine subsystems: rationality of taxi infrastructure configuration, the matching of passenger service facilities, collection and distribution efficiency, transfer efficiency, taxi dispatch efficiency, information service level, emergency service level, self-service level and full-course perception. Combined with the unique attributes of the airport hub, the composition and influencing factors of each subsystem are further refined, so that each subsystem is characterized by specific indicators. A set of clear, scientific and reasonable evaluation index system is established as shown in Table $1-9$.

Table 1. Evaluation index of rationality of taxi infrastructure configuration.

\begin{tabular}{|c|c|}
\hline Primary indicator & Secondary indicators \\
\hline \multirow{4}{*}{$\begin{array}{c}\text { Rationality of taxi } \\
\text { infrastructure } \\
\text { configuration }\end{array}$} & Number of taxi passages \\
\cline { 2 - 2 } & Scale of taxi storage yard \\
\cline { 2 - 2 } & Scale of taxi waiting area \\
\cline { 2 - 2 } & Parking facility rate \\
\cline { 2 - 2 } & Average turnover rate of the storage \\
& yard \\
\cline { 2 - 2 } & Intelligent parking level \\
\hline
\end{tabular}

Table 2. Evaluation index of the matching of passenger service facilities.

\begin{tabular}{|c|c|c|}
\hline $\begin{array}{c}\text { Primary } \\
\text { indicator }\end{array}$ & $\begin{array}{c}\text { Secondary } \\
\text { indicators }\end{array}$ & Tertiary indicators \\
\hline & & $\begin{array}{c}\text { Average number of } \\
\text { passengers in the peak } \\
\text { periods }\end{array}$ \\
\cline { 3 - 3 } $\begin{array}{c}\text { The matching of } \\
\text { passenger } \\
\text { service facilities }\end{array}$ & $\begin{array}{c}\text { Operation } \\
\text { efficiency of } \\
\text { Shuttle bus }\end{array}$ & $\begin{array}{c}\text { Average number of } \\
\text { passengers in the off- } \\
\text { peak periods }\end{array}$ \\
\cline { 3 - 3 } & $\begin{array}{c}\text { Average frequency of } \\
\text { departures in the peak }\end{array}$ \\
\hline
\end{tabular}

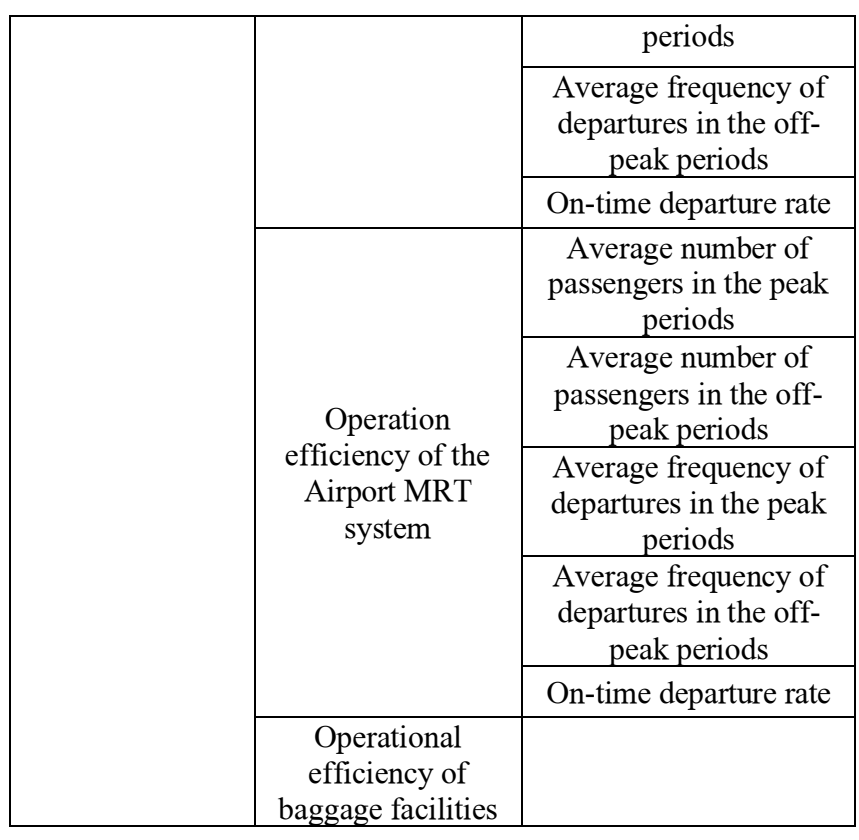

Table 3. Evaluation index of collection and distribution efficiency.

\begin{tabular}{|c|c|}
\hline Primary indicator & Secondary indicators \\
\hline \multirow{4}{*}{$\begin{array}{c}\text { Collection and } \\
\text { distribution } \\
\text { efficiency }\end{array}$} & $\begin{array}{c}\text { Average daily passenger flow into the } \\
\text { airport }\end{array}$ \\
\cline { 2 - 2 } & $\begin{array}{c}\text { Average daily passenger flow for taxi } \\
\text { transfer }\end{array}$ \\
\cline { 2 - 2 } & $\begin{array}{c}\text { Inflow of passengers to taxis during } \\
\text { peak hours }\end{array}$ \\
\cline { 2 - 2 } & Road traffic saturation \\
\cline { 2 - 2 } & Average evacuation time of passengers \\
\hline
\end{tabular}

Table 4. Evaluation index of transfer efficiency.

\begin{tabular}{|c|c|c|}
\hline $\begin{array}{l}\text { Primary } \\
\text { indicator }\end{array}$ & $\begin{array}{l}\text { Secondary } \\
\text { indicators }\end{array}$ & Tertiary indicators \\
\hline \multirow{10}{*}{$\begin{array}{l}\text { Transfer } \\
\text { efficiency }\end{array}$} & \multirow[t]{2}{*}{ Interchange distance } & $\begin{array}{l}\text { Transfer distances for } \\
\text { international } \\
\text { passengers } \\
\end{array}$ \\
\hline & & $\begin{array}{l}\text { Transfer distances for } \\
\text { domestic passengers }\end{array}$ \\
\hline & \multirow{2}{*}{$\begin{array}{l}\text { Average transfer } \\
\text { time }\end{array}$} & $\begin{array}{l}\text { Average transfer time } \\
\text { for international } \\
\text { passengers }\end{array}$ \\
\hline & & $\begin{array}{l}\text { Average transfer time } \\
\text { for domestic } \\
\text { passengers }\end{array}$ \\
\hline & \multirow{2}{*}{$\begin{array}{l}\text { Longest transfer } \\
\text { time }\end{array}$} & $\begin{array}{l}\text { Longest transfer time } \\
\text { for international } \\
\text { passengers }\end{array}$ \\
\hline & & $\begin{array}{l}\text { Longest transfer time } \\
\text { for domestic } \\
\text { passengers }\end{array}$ \\
\hline & $\begin{array}{c}\text { Average detour } \\
\text { coefficient }\end{array}$ & \\
\hline & \multirow{3}{*}{ Transfer comfort } & $\begin{array}{c}\text { Average queue length } \\
\text { of passengers during } \\
\text { peak hours }\end{array}$ \\
\hline & & $\begin{array}{l}\text { Maximum queue } \\
\text { length of passengers } \\
\text { during peak hours }\end{array}$ \\
\hline & & $\begin{array}{l}\text { Passenger congestion } \\
\text { at the taxi platform }\end{array}$ \\
\hline
\end{tabular}


Table 5. Evaluation index of taxi dispatch efficiency.

\begin{tabular}{|c|c|}
\hline Primary indicator & Secondary indicators \\
\hline \multirow{4}{*}{$\begin{array}{c}\text { Taxi dispatch } \\
\text { efficiency }\end{array}$} & The matching of taxi capacity \\
\cline { 2 - 2 } & Taxi dispatch speed during off-peak \\
hours
\end{tabular}

Table 6. Evaluation index of information service level.

\begin{tabular}{|c|c|}
\hline Primary indicator & Secondary indicators \\
\hline \multirow{4}{*}{$\begin{array}{c}\text { Information service } \\
\text { level }\end{array}$} & $\begin{array}{c}\text { Convenience of information } \\
\text { acquisition }\end{array}$ \\
\cline { 2 - 2 } & Timeliness of information acquisition \\
\cline { 2 - 2 } & Information accuracy \\
\cline { 2 - 2 } & $\begin{array}{c}\text { Intelligence degree of information } \\
\text { service }\end{array}$ \\
\hline
\end{tabular}

Table 7. Evaluation index of emergency service level.

\begin{tabular}{|c|c|}
\hline Primary indicator & Secondary indicators \\
\hline \multirow{4}{*}{$\begin{array}{c}\text { Emergency service } \\
\text { level }\end{array}$} & \begin{tabular}{c} 
Passenger density in key areas \\
\cline { 2 - 2 }
\end{tabular} \\
\cline { 2 - 2 } & $\begin{array}{c}\text { Accuracy rate of early warning of } \\
\text { major events }\end{array}$ \\
\cline { 2 - 2 } & $\begin{array}{c}\text { Timeliness of emergency evacuation } \\
\text { plan }\end{array}$ \\
\cline { 2 - 2 } & $\begin{array}{c}\text { Relief efficiency of passenger flow } \\
\text { emergency } \\
\text { under emergency }\end{array}$ \\
\hline
\end{tabular}

Table 8. Evaluation index of self-service level.

\begin{tabular}{|c|c|}
\hline $\begin{array}{c}\text { Primary } \\
\text { indicator }\end{array}$ & Secondary indicators \\
\hline \multirow{4}{*}{ Self-service level } & Supply of self-service facilities \\
\cline { 2 - 2 } & The queue time of self-service facilities \\
\cline { 2 - 2 } & Response speed of self-service facilities \\
\cline { 2 - 2 } & Self-service satisfaction \\
\hline
\end{tabular}

Table 9. Evaluation index of the full-course perception.

\begin{tabular}{|c|l|}
\hline Primary indicator & Secondary indicators \\
\hline $\begin{array}{c}\text { Full-course } \\
\text { perception }\end{array}$ & Passenger satisfaction \\
\hline
\end{tabular}

\subsection{The meaning of evaluation indexes}

The meaning of each evaluation index is explained as follows.

\subsubsection{Rationality of taxi infrastructure configuration}

The rationality of taxi infrastructure configuration includes the following indicators:

Number of taxi passages: it reflects the number of taxi passages at the airport hub.
Scale of taxi storage yard: it reflects the area of taxi storage yard.

Scale of taxi waiting area: the taxi waiting area mainly provides taxi parking waiting service, reflecting the size of the waiting area.

Parking facility rate: it reflects the level of airport hubs providing parking conditions for taxis, and it is the ratio of the existing capacity of the car park to the capacity to be set.

$$
\text { Parking facility rate }=\frac{F_{b}}{F_{m}}
$$

Where, $F_{b}$ is existing capacity of the car park, $F_{m}$ is the capacity to be set of the car park.

Lane-side facility rate: reflects the level of lane-side conditions provided by the airport hub for taxis, and it is the ratio of the existing capacity of the lane-side to the capacity to be set.

$$
\text { Lane }- \text { side facility rate }=\frac{E_{b}}{E_{m}}
$$

Where, $E_{b}$ is existing capacity of the lane-side, $E_{m}$ is the capacity to be set of the lane-side.

Average turnover rate of the storage yard: it reflects the turnover of the storage yard, the average number of parking times for each parking yard in the storage yard within a certain period of time, which is the ratio of the number of vehicles entering the storage yard per unit time and the number of vehicles in the storage yard.

Intelligent parking level: it reflects the perfection and intelligence of the parking service at the hub.

\subsubsection{The matching of passenger service facilities}

Operation efficiency of Shuttle bus: it is further broken down into the average number of passengers, average frequency of departures (every few minutes apart) in the peak and off-peak periods, and on-time rate (ontime departure rate of the shuttle bus, reflecting the delay of the shuttle bus).

Operation efficiency of the Airport MRT system: it is further broken down into the average number of passengers, average frequency of departures (every few minutes apart) in the peak and off-peak periods, and the on-time rate (on-time departure rate of the MRT system, reflecting the delay of the MRT system).

Operational efficiency of baggage facilities: it reflects the efficiency of the baggage facilities at the airport hub to provide passengers with baggage services. It is expressed in terms of the time from the time passengers get off the plane to get the baggage at the baggage carousel.

\subsubsection{Collection and distribution efficiency}

Average daily passenger flow into the airport: the average daily passenger flow into the hub reflects the distribution scale of the airport's comprehensive transportation network (person-times/day).

Average daily passenger flow for taxi transfer: the average daily passenger flow of the hub transferring to taxis reflects the distribution scale of taxi capacity (person-times/day). 
Inflow of passengers to taxis during peak hours: it reflects the passengers transferring to taxis during peak hours of passenger traffic at the hub (persons/hour).

Road traffic saturation: it is the ratio of road's actual vehicle flow to design flow of the airport's comprehensive transportation network, reflecting whether the road capacity of the existing transportation network of the airport meets the requirements. It is the ratio of the peak hour traffic flow (vehicles/hour) to the designed traffic flow around the hub.

$$
\text { Road Traffic Saturation }=\frac{\sum_{i=1}^{n} \frac{N_{v i}}{C_{r i}} \times N_{v i}}{\sum_{i=1}^{n} N_{v i}}
$$

Where, $N_{v i}$ is Peak hour traffic volume of the i-th road in the airport hub network (vehicles/hour), $C_{r i}$ is the design capacity of the i-th road.

Average evacuation time of passengers: it is the average evacuation time of passengers who transfer to a taxi from the airport to the urban area, reflecting the convenience level of the airport's comprehensive transportation network.

\subsubsection{Transfer efficiency}

Interchange distance: it is further subdivided into international and domestic passenger interchange distances, which are the distances from the exit of the aircraft to the customs, border control, inspection and quarantine area, luggage area, and then to the taxi waiting area, reflecting the reasonableness of the design of the hub transfer taxi flow line.

Average transfer time: it is further subdivided into the average transfer time for international and domestic passengers, reflecting the time it takes for passengers to handle business from disembarkation to customs, border control, inspection and quarantine areas, baggage claim to taxi waiting area, and taxi waiting time. It is the average of the sum of the above times.

Longest transfer time: it is further subdivided into the longest transfer time for international and domestic passengers, reflecting the time it takes for passengers to handle business from disembarkation to customs, border control, inspection and quarantine area, baggage claim to taxi waiting area, and taxi waiting time. It is the maximum value of the sum of the above times.

Average detour coefficient: it reflects the detour distance of passengers during the transfer process. It is the ratio of the actual distance travelled by passengers to the ideal distance, such as the straight-line distance between start point and end point, and the value of detour coefficient represents the layout characteristics of the hub facilities.

Transfer comfort: it is further subdivided into the average queue length of passengers during peak hours (average length of queues for passengers in the taxi waiting area during peak hours), the maximum queue length of passengers during peak hours (maximum length of passengers in queues during peak hours), and the passenger congestion at the taxi platform (reflecting the degree of congestion of passengers at the taxi platform, expressed as the ratio of taxi passenger platform area to peak hour passenger flow).

\subsubsection{Taxi dispatch efficiency}

The matching of taxi capacity: it reflects the coordination of taxi capacity and passenger flow in the airport's comprehensive transportation network, based on the comprehensive calculation of the predicted value of passenger flow by taxi, the number of passengers in line at the platform, the number of taxis in the waiting area, and the estimated supplementary taxi capacity, etc. It is used to express the matching situation of taxi capacity and taxi transport passenger flow, which is the ratio of taxi passenger transfer demand to taxi capacity.

$$
\text { Taxi capacity matching }=\frac{\left(P_{p}+P_{w}\right) / \lambda}{C_{w}+C_{P}}
$$

Where, $P_{p}$ is the predicted value of passenger flow by taxi, $P_{w}$ is the number of passengers in line at the platform, $\lambda$ is average number of passengers in a taxi, $C_{w}$ is the number of taxis in the waiting area, $C_{p}$ is The predicted value of the taxi's supplementary capacity.

Taxi dispatch speed during off-peak hours: it reflects the time required from issuing a taxi dispatch instruction to the taxi arriving at the waiting area during off-peak passenger arrivals.

Taxi dispatch speed during peak hours: it reflects the time required from issuing a taxi dispatch instruction to the taxi arriving at the waiting area during peak passenger arrivals.

Average queue length of taxi: it reflects the average length of taxi queue in the lane where the taxi is boarding.

Average queue time of taxi: it reflects the average queue time of each taxi in the lane of the boarding area of the taxi waiting area.

Passenger relief efficiency: it reflects the maximum number of passengers (persons/hour) that taxis can relieve during peak hours. We can continuously count $n$ hours to calculate the maximum number of passengers that can be evacuated by taxi in a unit hour.

\subsubsection{Information service level}

Convenience of information acquisition: it reflects the convenience of passengers to obtain flight, vehicle, luggage, route and other information in the hub through signs, broadcasts, display screens, mobile phones and other channels.

Timeliness of information acquisition: it reflects the speed of passengers getting traffic operational information such as taxi capacity and time in the hub.

Information accuracy: it reflects the deviation between the content of the operation information such as taxi capacity and the time which obtained by passengers and actual information in the hub.

Intelligence degree of information service: it reflects the hub's information technology level and the comprehensive intelligence degree of passengers receiving information services, such as luggage tracking service, comprehensive traffic information service, etc. 


\subsubsection{Emergency service level}

Passenger density in key areas: it reflects the density of people in high-density areas such as baggage claim hall exits, key passages, and taxi waiting areas, etc. It is the number of passengers per unit area (number/area).

Accuracy rate of early warning of major events: it reflects the ratio of the number of major events (such as large area flight delays) predicted and plans implemented to the number of all major events.

Timeliness of emergency evacuation plan: it reflects the timeliness of passengers getting emergency evacuation plan push in emergency.

Taxi dispatch efficiency under emergency: it reflects the time required from issuing the taxi dispatch instruction to the taxi arriving at the waiting area under emergency conditions such as large area flight delays.

Relief efficiency of passenger flow under emergency: it reflects the maximum number of passengers (number/hour) that can be evacuated per hour per taxi under emergency.

\subsubsection{Self-service level}

Supply of self-service facilities: it reflects the number of self-service facilities such as navigation and guidance equipment in key areas.

The queue time of self-service facilities: it reflects the average queue time of passengers handling business in self-service facilities.

Response speed of self-service facilities: it reflects the response speed of the self-service system.

Self-service satisfaction: it reflects the overall satisfaction of passengers with self-service.

\subsubsection{Full-course perception}

Full-course perception: it is measured by the passenger satisfaction index, reflecting the passenger's overall satisfaction with the taxi transfer process at the airport hub.

\section{Research on evaluation index calculation and evaluation method}

\subsection{Evaluation index calculation}

The data sources of the taxi operation and service evaluation index system in airport hubs constructed in table 1-9 include: on-site and questionnaire surveys, collecting data from information systems, constructing models to calculate indicators, and combining use of various methods. Some index values can be obtained directly through surveys, expert interviews, or certain calculations; some indexes need to be calculated by extracting data from information systems, for example, the data of passenger density and queuing situation can be obtained from the video information system and calculated by video analysis technology combined with surveys. In addition, some indicators need to specially construct models to use big data technology to calculate, including: the real-time prediction of inbound flight passenger flow, taxi sharing rate and taxi capacity. Through the calculation of the above indicators, combined with the actual situation of the airport hub, the taxi capacity gap can be calculated, so as to provide scientific basis for taxi capacity warning and dispatch.

\subsubsection{Build index calculation models}

Air passengers have characteristics of uneven distribution in time and space, variable high density, etc. Passenger flow and baggage flow are drawn by flight flow. Whether or not it is possible to accurately predict the passenger flow in a certain period in the future is an important prerequisite for evaluating the efficiency of taxi capacity distribution and making taxi matching and dispatching in advance for the passenger flow transferring to taxis. The current commonly used passenger traffic prediction methods include: based on statistics, regression, time series, neural networks and machine learning technology. Machine learning technology has better prediction effect on prediction problems with many influencing factors and complex relationships, and has become a widely used prediction method. Among them, XGBoost is a more popular machine learning technology ${ }^{[8]}$. For flight passenger flow prediction, the XGBoost algorithm has better prediction effect, faster algorithm running speed, and strong practicability ${ }^{[1]}$.

Similar to the prediction process of real-time incoming flight passenger flow, the XGBoost algorithm combined with Logistic regression also can be used to model the prediction of taxi sharing rate of the incoming flight passenger flow and the supplementary taxi capacity. The forecasting process generally includes: data collection, data preprocessing, feature construction, training sample construction, model construction and training, and using the instance data of the airport to verify the experimental results, then we can obtain prediction results about realtime incoming passenger flow, real-time taxi sharing ratio and supplementary taxi capacity.

\subsubsection{Extract data from information systems and analyze}

Through collecting passenger and taxi monitoring video data in key areas and using the video monitoring system and analysis technology, we can analyze the passenger flow, the density and distribution status of each area, and analyze the travel time of passengers' walking, queuing, waiting, etc., and monitor abnormal conditions such as passenger congestion and high passenger traffic ${ }^{[9]}$. Meanwhile, we can analyze the traffic flow data such as operating status, the numbers and queuing length of taxis, and monitor taxi capacity allocation. Through the perception and analysis of passenger and taxi information, it provides a basis for the automatic acquisition and calculation of indicators related to distribution, transfer, taxi dispatch efficiency, and service level in airport hubs.

\subsection{Evaluation method}


With the development of big data technology, new ideas for studying comprehensive evaluation theories and methods in the context of big data have gradually become a new trend. Constructing the key technology of comprehensive evaluation combining traditional evaluation methods and big data methods has important theoretical significance and practical value for the improvement of the comprehensive evaluation method system. The key technologies of comprehensive evaluation integrate with knowledge engineering and computer systems, and transform some complex system problems from knowledge models to computer models, so as to integrate expert knowledge and experience with various objective data, and comprehensively integrate from qualitative to quantitative ${ }^{[10]}$.

By building an scientific index system and obtaining diversified data and calculating indexes based on surveys, expert experience, information system data extraction and model construction, the paper comprehensively evaluate the taxi operation and service of airport hubs by using the constructed comprehensive evaluation key technology, and then the level and weakness of the capacity of taxis can be concluded. For indicators that do not meet the requirements of the operation and service standards, the association relationship graph is constructed by setting association rules. And key factors that affect the performance of the indicators can be analyzed to obtain the main reasons that affect efficiency and service quality, so as to provide scientific decision-making basis for the optimization and improvement of taxi operation and service.

\section{Conclusion}

Promoting the in-depth integration of the hub airport with other modes of transportation, and building an airport comprehensive passenger hub with hub airports as the core is important measure for the construction of international aviation hub. And the perfect collection and distribution system is a key factor that reflects the function of airport hubs.

The construction of the evaluation index system of the taxi operation and service considers the impact of the application of current new technologies on the hub collection and distribution system. And the evaluation indexes for taxi capacity monitoring, coordinated dispatch, emergency evacuation, and self-service are designed. The establishment of the index system will provide a strong reference for the evaluation index establishment of other transportation modes and the hub as a whole. Based on the evaluation index system, evaluation standards will be established for the construction of smart comprehensive transportation platform for airport hubs. Through the construction, application and promotion of scientific and standardized standard systems, the level of institutionalization of comprehensive transportation operations and services in airport hubs will be improved, and the construction of smart airports in China will be facilitated.

\section{Acknowledgment}

This work was supported in part by the National Key Research and Development Program of China (No. 2018YFB1601200), supported in part by the Civil Aviation Big Data and Smart Airport Laboratory (Baiyun Information Technology Co.,Ltd-CAMIC).

\section{References}

1. R. Jia, X. Ran, J. Wu etc, Airport Passenger Flow Prediction Based on XGBoost Algorithm. Journal of civil aviation, 2 (2018)

2. Y. Han, W. Zhou, Four dimensions model for passenger transport hub operation service quality evaluation. Journal of Chang'an University(Natural Science Edition), 34 (2014)

3. X. Wei, Research on the evaluation and optimization of transfer facilities in Railway Comprehensive Passenger Transport Hub. Beijing: Beijing Jiaotong University, (2019)

4. Q. Zhang, B. Han, D. Li, etc, Evaluation Method for the Operation Performance of Urban Rail Transit Hub Based on Simulation Technology. China railway science, 05 (2011)

5. Q. Zhang, Z. Jiang, D. Liu, etc, The Multi-objective Optimization Problem of the Comprehensive Passenger Transport Hub Connecting Transport Coordination Scheduling. Journal of Changchun University of Science and Technology(Natural Science Edition) ,41 (2018)

6. Z. Zhao, J. Yao, Evaluation of transfer at high-speed railway passenger terminal based on multi-level extensible method. Journal of Railway Science and Engineering, 13 (2016)

7. C. Qin. Study on the planning of Ground Acess System for Mega-Airports. Shanghai: Tongji University, (2007)

8. T. Chen, T. He, Higgs Boson Discovery with Boosted Trees. JMLR: Workshop and Conference Proceedings, 42 (2015)

9. Y. Liu, X. Wang, etc, Extraction and Analysis of Passenger Flow Features of Airport Terminal Building Based on Information System. Air Freight Business, 4 (2020)

10. Y. Li, Research on Intelligent Comprehensive Evaluation Method in Big Data Environment. Academic Forum, 37 (2014) 